\title{
NOTES
}

\section{Enhancement of Isotacticity in Bulk Radical Polymerization of Poly(methyl methacrylate) under Strong Gravity Field}

\author{
Masamichi Nishinara, Koji Teramoto, Toshihiko Sakurai, Makoto TaKafuji, \\ Tsutomu MASHIMO, ${ }^{*}$ and Hirotaka IHARA ${ }^{\dagger}$ \\ Department of Applied Chemistry \& Biochemistry, Faculty of Engineering \\ * Shock Wave and Condensed Matter Research Center, Kumamoto University, \\ Kurokami, Kumamoto 860-8555, Japan
}

(Received September 9, 2002; Accepted January 20, 2003)

KEY WORDS Poly(Methyl Methacrylate)(PMMA) / Centrifugation / Strong Gravity Field /
Tacticity / ${ }^{1}$ H NMR spectroscopy / Isotacticity /

Stereoregular polymers are one of the most important materials in industry due to its thermostability, stiffness and chemical resistance. Stereoregular polymers have been prepared by polymerization with metal catalysts such as Ziegler-Natta catalysts. They have been extensively studied by the polymerization with Grignard reagents, alkylaluminum and alkyllithium. ${ }^{1}$ On the other hand, control of stereoregularity without metal catalysts should be valuable. For this purpose, it has been reported the polymerizations of methacrylates having bulky side chains. ${ }^{2}$ However, this idea provides limitation of chemical structures in monomers and then may be less applicable to extend.

In this study, we aim to increase stereoregularity in free radical bulk polymerization of general-purpose monomers without special metal catalyst. Therefore, we focused on the polymerization under strong gravity field over $10^{5} \mathrm{~g}$ although there has been a few reports under gravity field of $10^{4} \mathrm{~g} \mathrm{level}^{3}$ and their research aims are not related to stereoregularity., ${ }^{3,4}$ Fortunately, one of the authors has established the sedimentation theory under mega gravity field ${ }^{5}$ and also developed the centrifugal apparatus generated over $10^{6}$ g. ${ }^{6}$ This gravity field can induce the sedimentation of metal atoms in solid-solution system alloy. ${ }^{7}$ If monomers have a deviated center of gravity and are exposed to strong gravity field, the polymerization may proceed with molecular orientation of the monomers. In this study, methyl methacrylate was used as a monomer. The tacticity of the resultant poly(methyl methacrylate) (PMMA) was measured by ${ }^{1} \mathrm{H}$ NMR spectroscopy.

${ }^{\dagger}$ To whom correspondence should be addressed.

\section{EXPERIMENTAL}

\section{Materials}

Methyl methacrylate (MMA; Nacalai tesque, Japan) was distilled and the fraction at $45^{\circ} \mathrm{C}(65 \mathrm{mmHg})$ was used. 2,2'-Azobisisobutyronitrile (AIBN; Nacalai tesque, Japan), 2,2'-azobis(2,4-dimethylvaleronitrile) (ADVN; Wako pure chemical, Japan) as initiators and benzylmercaptan (BM; Tokyo Kasei Kogyo, Japan) as a telogen was used. AIBN was purified by recrystallization from methanol. ADVN and BM were used as received. Polymerization of MMA was carried out in a stainless steel centrifugal tube $(3 \mathrm{~mm}$ i.d. $\times 8.5 \mathrm{~mm})$. A $50 \mu \mathrm{L}$ of monomer solution was put into the tube. The tube was sealed tightly by a stainless steel cap. Polymerization was also carried out under $1 \mathrm{~g}$ by the similar procedure.

\section{Centrifugation}

Strong gravity field was generated by the centrifugal apparatus which was designed by one of the authors (Figure 1). ${ }^{6}$ This ultracentrifuge can be characterized by strong gravity field of over 1 million $g$ at constant temperature within $\pm 2{ }^{\circ} \mathrm{C}$. However, the temperature at the rotor room measured with a thermocouple was influenced by the rotating speed because of friction of air. This caused limitation in experimental conditions: e.g., to keep at $35^{\circ} \mathrm{C}$, the rotation speed must be within $66000 \mathrm{rpm}$ which corresponds to $9 \times 10^{4} \mathrm{~g}$ at the bottom of a centrifugal tube. The other limits of the rotation speeds were $15 \times 10^{4} \mathrm{rpm}\left(45 \times 10^{4} \mathrm{~g}\right)$ at $60^{\circ} \mathrm{C}$, $17 \times 10^{4} \mathrm{rpm}\left(58 \times 10^{4} \mathrm{~g}\right)$ at $95^{\circ} \mathrm{C}$ and $20 \times 10^{4} \mathrm{rpm}$ $\left(83 \times 10^{4} \mathrm{~g}\right)$ at $150^{\circ} \mathrm{C}$. In case of the gravity field of 

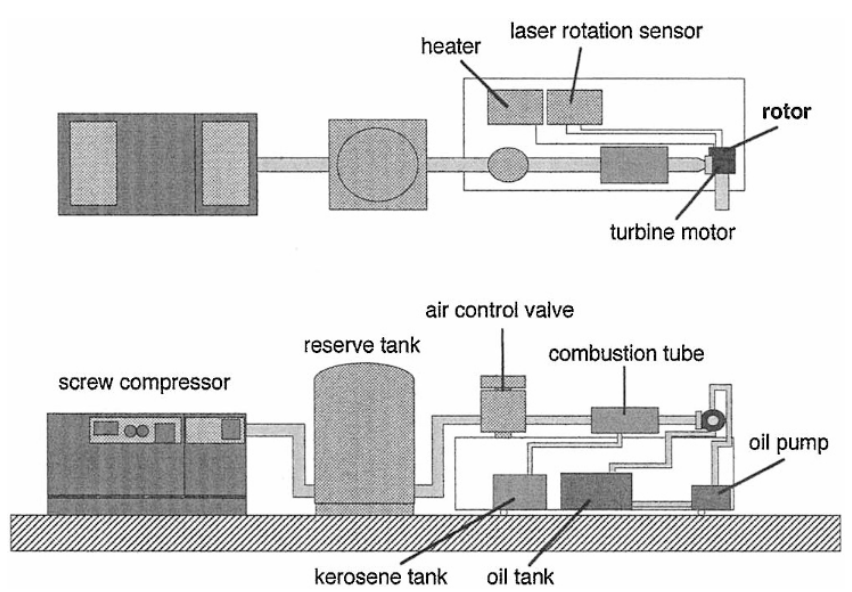

Figure 1. Schematic layout of the ultracentrifuge apparatus.

$1 \times 10^{4} \mathrm{~g}(8000 \mathrm{rpm})$, centrifugation was used with an ultracentrifuge machine of H-200N (Kokusan, Ltd.) and a plastic capsule $(16 \mathrm{~mm}$ i.d. $\times 80 \mathrm{~mm})$.

\section{Measurements}

${ }^{1} \mathrm{H}$ NMR spectra were obtained with JNM-EX400 (JEOL) at $400 \mathrm{MHz}$. The tacticities of PMMA were determined by these spectra in $\mathrm{CDCl}_{3}$ with $0.03 \% \mathrm{TMS}$ as described by White and Filisco. 8

SEC was performed on a Waters 966 chromatograph equipped with Tosoh column Super HM-M $(6 \mathrm{~mm}$ i.d. $\times 150 \mathrm{~mm}$ ) using tetrahydrofuran (THF) as an eluent at room temperature.

\section{RESULTS AND DISCUSSION}

\section{Effect of Initiator Concentration}

Effect of initiator concentrations to the tacticity was examined by various ratios of methyl methacrylate (MMA) and AIBN. A typical NMR spectrum of the resultant poly(methyl methacrylate) (PMMA) obtained under $29 \times 10^{4} \mathrm{~g}$ was shown in Figure 2. Tacticities were estimated by $\alpha-\underline{\mathrm{C}}_{3}$ peaks of PMMA. ${ }^{8}$ These were assigned to be isotactic, atactic and syndiotactic conformations at $1.31-1.16,1.11-0.95$, and $0.95-$ 0.72 ppms, respectively. Table I shows the tacticities in PMMA prepared under $29 \times 10^{4} \mathrm{~g}$ and $1 \mathrm{~g}$. It was confirmed that the isotactic conformations in the centrifugal samples were higher than those in the controlled samples which were obtained under $1 \mathrm{~g}$. It indicates that strong gravity field increases the isotacticity. However, no significant difference was found for initiator concentrations.

Here, it should be discussed how stereoregularity increased under the high gravity field. Methyl methacrylate has an oxygen atom in a side chain, which is heavier than a carbon atom, to cause deviation of the molecular gravity center. It is estimated that the molecule can

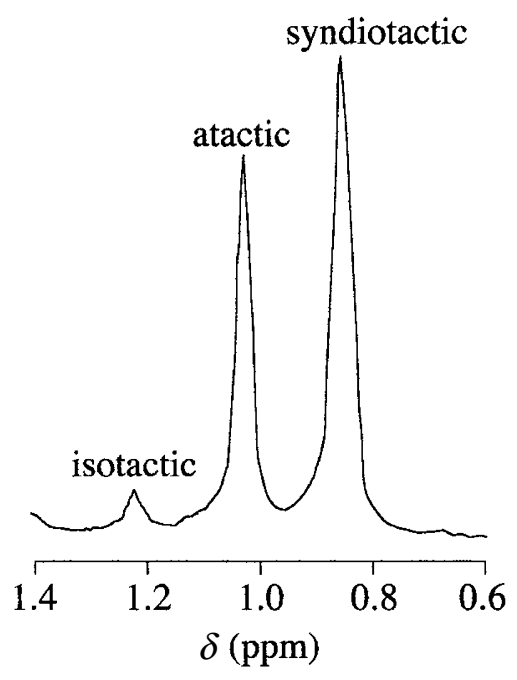

Figure 2. ${ }^{1} \mathrm{H}$ NMR spectrum of $\alpha-\underline{\mathrm{C}}_{3}$ of PMMA in $\mathrm{CDCl}_{3}$ $\left([\mathrm{MMA}]:[\mathrm{AIBN}]=100000: 1,60^{\circ} \mathrm{C}, 29 \times 10^{4} \mathrm{~g}, 47 \mathrm{~h}\right.$ ).

order to the direction of the gravity field. If such ordered monomers are polymerized under the high gravity field, isotacticity can be dominated rather than syndiotacticity in the resultant polymer. This estimation is supported by the report of Regen et al. ${ }^{9}$ They reported that the isotacticity of poly(methacrylic acid) increased by highly-ordered media such as lipid bilayer membranes.

\section{Effect of Strength of Gravity Field}

Centrifugation was performed under the gravity field of $1 \times 10^{4} \mathrm{~g}$ and $29 \times 10^{4} \mathrm{~g}$ to investigate the influence of strength of gravity field. As shown in Table II, there was no significant difference between the centrifugal samples prepared under $1 \times 10^{4} \mathrm{~g}$ and the controlled samples prepared under $1 \mathrm{~g}$. However, isotactic conformations prepared under $29 \times 10^{4} \mathrm{~g}$ were approximately $30 \%$ higher than those of controlled samples. Unfortunately, it was difficult to observe with stronger gravity field than $29 \times 10^{4} \mathrm{~g}$ because further increase of acceleration (rise of rotating speed) caused rise of the experimental temperature by friction of air, but it indicates that isotacticity can be promoted by exposing strong gravity field to monomers.

\section{Effect of Temperature}

Temperature effect on stereoregularity was investigated. The results were summarized in Table III. The isotactic conformations in all samples increased with rise of temperature although the syndiotactic comformations decreased. This indicates that the formation of isotactic conformation is dominated at higher temperature. Similar result have been reported by Asai et al. ${ }^{10}$ It can be explained that it is easier to obtain the energy to convert into isotactic polymers at high temperature. 
Table I. Tacticity to the various kinds of initiator concentrations and ratio of tacticity in centrifugal samples ${ }^{\mathrm{a}}$

\begin{tabular}{|c|c|c|c|c|c|c|c|c|c|}
\hline \multirow{3}{*}{$\begin{array}{l}\text { MMA : AIBN } \\
\quad(\mathrm{mol})\end{array}$} & \multicolumn{6}{|c|}{ tacticity } & \multirow{2}{*}{\multicolumn{3}{|c|}{ ratio $^{\mathrm{b}}$}} \\
\hline & \multicolumn{3}{|c|}{ controlled samples $(\%)$} & \multicolumn{3}{|c|}{ centrifugal samples $(\%)$} & & & \\
\hline & iso & atactic & syndio & iso & atactic & syndio & iso & atactic & syndio \\
\hline $1000: 1$ & $3.4 \pm 0.26$ & $34 \pm 0.24$ & $63 \pm 0.40$ & $4.4 \pm 0.31$ & $36 \pm 0.15$ & $60 \pm 0.17$ & 1.3 & 1.1 & 0.96 \\
\hline $10000: 1$ & $3.6 \pm 0.43$ & $33 \pm 0.91$ & $63 \pm 0.74$ & $4.0 \pm 0.21$ & $35 \pm 0.11$ & $61 \pm 0.21$ & 1.1 & 1.0 & 0.97 \\
\hline $100000: 1$ & $3.2 \pm 0.39$ & $32 \pm 1.1$ & $65 \pm 1.5$ & $4.1 \pm 0.25$ & $35 \pm 0.22$ & $61 \pm 0.33$ & 1.3 & 1.1 & 0.96 \\
\hline
\end{tabular}

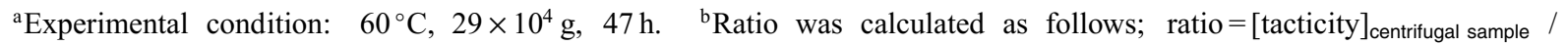
[tacticity $]_{\text {controlled sample. }}$

Table II. Tacticity to the various kinds of gravity field and ratio of tacticity in centrifugal samples

\begin{tabular}{|c|c|c|c|c|c|c|c|c|c|}
\hline \multirow{3}{*}{$\begin{array}{c}\text { Gravity } \\
\left(\times 10^{4} \mathrm{~g}\right)\end{array}$} & \multicolumn{6}{|c|}{ tacticity } & \multirow{2}{*}{\multicolumn{3}{|c|}{ ratio $^{c}$}} \\
\hline & \multicolumn{3}{|c|}{ controlled samples (\%) } & \multicolumn{3}{|c|}{ centrifugal samples $(\%)$} & & & \\
\hline & iso & atactic & syndio & iso & atactic & syndio & iso & atactic & syndio \\
\hline $1^{\mathrm{a}}$ & $3.2 \pm 0.12$ & $33 \pm 0.41$ & $64 \pm 0.49$ & $3.5 \pm 0.53$ & $33 \pm 0.57$ & $63 \pm 0.68$ & 1.1 & 1.0 & 1.0 \\
\hline $29^{b}$ & $3.2 \pm 0.39$ & $32 \pm 1.1$ & $65 \pm 1.5$ & $4.1 \pm 0.25$ & $35 \pm 0.22$ & $61 \pm 0.33$ & 1.3 & 1.1 & 0.96 \\
\hline
\end{tabular}

${ }^{\mathrm{a}}$ Experimental condition: MMA $(\mathrm{mol}): \mathrm{AIBN}(\mathrm{mol})=1000: 1,60^{\circ} \mathrm{C}, 49 \mathrm{~h} .{ }^{\mathrm{b}}$ Experimental condition: MMA (mol) : AIBN $(\mathrm{mol})=100000: 1,60^{\circ} \mathrm{C}, 47 \mathrm{~h} .{ }^{\mathrm{c}}$ Ratio was calculated as follows; ratio $=[\text { tacticity }]_{\text {centrifugal sample }} /[\text { tacticity }]_{\text {controlled sample }}$.

Table III. Tacticity to the various kinds of experimental temperature and ratio of tacticity in centrifugal samples

\begin{tabular}{|c|c|c|c|c|c|c|c|c|c|}
\hline \multirow{3}{*}{$\begin{array}{l}\text { temperature } \\
\quad\left({ }^{\circ} \mathrm{C}\right)\end{array}$} & \multicolumn{6}{|c|}{ tacticity } & \multirow{2}{*}{\multicolumn{3}{|c|}{ ratio $^{c}$}} \\
\hline & \multicolumn{3}{|c|}{ controlled samples $(\%)$} & \multicolumn{3}{|c|}{ centrifugal samples (\%) } & & & \\
\hline & iso & atactic & syndio & iso & atactic & syndio & iso & atactic & syndio \\
\hline $35^{\mathrm{a}}$ & $3.1 \pm 0.03$ & $32 \pm 0.50$ & $65 \pm 0.53$ & $3.1 \pm 0.16$ & $32 \pm 0.18$ & $65 \pm 0.22$ & 1.0 & 1.0 & 1.0 \\
\hline $60^{\mathrm{b}}$ & $3.4 \pm 0.26$ & $34 \pm 0.24$ & $63 \pm 0.40$ & $4.4 \pm 0.31$ & $36 \pm 0.15$ & $60 \pm 0.17$ & 1.3 & 1.1 & 0.96 \\
\hline $95^{\mathrm{c}}$ & $4.9 \pm 0.04$ & $38 \pm 0.47$ & $57 \pm 0.50$ & $5.7 \pm 0.13$ & $38 \pm 0.47$ & $57 \pm 0.50$ & 1.2 & 1.0 & 0.98 \\
\hline $150^{\mathrm{d}}$ & $8.1 \pm 0.61$ & $43 \pm 6.3$ & $49 \pm 5.7$ & $8.0 \pm 0.23$ & $43 \pm 0.12$ & $49 \pm 0.31$ & 1.0 & 1.0 & 1.0 \\
\hline
\end{tabular}

${ }^{\mathrm{a}}$ Experimental condition: $9 \times 10^{4} \mathrm{~g}, 100 \mathrm{~h}, \mathrm{MMA}+\mathrm{ADVN}(\mathrm{MMA}(\mathrm{mol}): \mathrm{ADVN}(\mathrm{mol})=1000: 1) .{ }^{\mathrm{b}}$ Experimental condition: $29 \times 10^{4} \mathrm{~g}, 47 \mathrm{~h}, \mathrm{MMA}+\mathrm{AIBN}(\mathrm{MMA}: \mathrm{AIBN}=1000: 1) .{ }^{\mathrm{c}}$ Experimental condition: $58 \times 10^{4} \mathrm{~g}, 24 \mathrm{~h}$, MMA. ${ }^{\mathrm{d}}$ Experimental condition: $83 \times 10^{4} \mathrm{~g}, 5 \mathrm{~h}, \mathrm{MMA} .{ }^{e}$ Ratio was calculated as follows; ratio $=[\text { tacticity }]_{\text {centrifugal sample }} /[\text { tacticity }]_{\text {controlled sample }}$.

Table IV. Tacticity to the various concentrations of benzylmercaptan and ratio of tacticity in centrifugal samples ${ }^{\mathrm{a}}$

\begin{tabular}{|c|c|c|c|c|c|c|c|c|c|}
\hline \multirow{3}{*}{ MMA : BM } & \multicolumn{6}{|c|}{ tacticity } & \multirow{2}{*}{\multicolumn{3}{|c|}{ ratio $^{\mathrm{b}}$}} \\
\hline & \multicolumn{3}{|c|}{ controlled samples $(\%)$} & \multicolumn{3}{|c|}{ centrifugal samples (\%) } & & & \\
\hline & iso & atactic & syndio & iso & atactic & syndio & iso & atactic & syndio \\
\hline $10: 1$ & 4.8 & 37 & 59 & 6.8 & 40 & 54 & 1.2 & 1.1 & 0.92 \\
\hline $20: 1$ & 6.1 & 35 & 59 & 6.5 & 38 & 56 & 1.1 & 1.1 & 0.94 \\
\hline $100: 1$ & 4.7 & 35 & 61 & 9.4 & 34 & 57 & 2.0 & 0.97 & 0.94 \\
\hline
\end{tabular}

${ }^{\text {a }}$ Experimental condition: $60^{\circ} \mathrm{C}, 45 \times 10^{4} \mathrm{~g}, 48 \mathrm{~h}$. ${ }^{\mathrm{b}}$ Ratio was calculated as follows; ratio = $[\text { tacticity }]_{\text {centrifugal sample }} /[\text { tacticity }]_{\text {controlled sample }}$.

On the other hand, the ratios of isotactic conformations in the resultant polymers prepared at 60 and $95^{\circ} \mathrm{C}$ were observed 1.2 and 1.3 , respectively. On the contrary, the ratios of isotactic conformations at 35 and $150^{\circ} \mathrm{C}$ were 1.0 and showed no significant change. As reported Asai et al., syndiotactic polymers are dominantly prepared in low temperature polymerization such as $35^{\circ} \mathrm{C}$. It is estimated that enhancement of isotacticity at $35^{\circ} \mathrm{C}$ could not be observed because the formation energy of syndiotactic polymers at $35^{\circ} \mathrm{C}$ overcame gravity force for orienting monomer molecules. On the other hand, isotactic polymers are dominantly prepared in polymerization at high temperature although molecular mobility of monomers would rise at high temperature. Strong molecular mobility at high temperature would disturb the formation of oriented structure by gravity force and isotacticity of centrifugal samples would be same as those of controlled samples. These results indicate that monomer temperature plays the important role of the control of tacticity.

\section{Effect of a Telogen}

In general, stereoregular polymers have been readily obtained in relatively smaller molecular weight. Therefore, telomerization was carried out under strong gravity field using benzylmercaptan as a telogen to reduce 
the molecular weight. In case of polymerization with benzylmercaptan, ${ }^{1} \mathrm{H}$ NMR spectrum was measured once because small recovery of the resultant polymers.

In case of low polymerization degree polymers, we had to consider the effects on the chain-end unit of polymers in ${ }^{1} \mathrm{H}$ NMR spectra. Therefore, tacticities on PMMA with BM were determined at fractions of 1.31$1.18,1.11-0.93$, and $0.93-0.72$ ppms as isotactic, atactic and syndiotactic conformations, respectively.

The isotactic conformations of centrifugal samples were observed 1.1-2.0 times higher than those of the controlled samples (Table IV). The polymerization degrees of the telomers were estimated to be 1100-12000 by SEC in THF. These values are much smaller than the polymerized samples (more than 300000). It indicates that the molecular weight also affected the increase of the isotactic conformation.

\section{CONCLUSIONS}

A novel method was proposed for preparing stereoregular polymers under strong gravity field (29$83 \times 10^{4} \mathrm{~g}$ ) by free radical bulk polymerization. The most isotactic-rich polymer was the polymer prepared by using a benzylmercaptan and this value showed 2.0 times higher than that of the controlled polymer. It indicates that it is possible to control the stereoregularity by polymerization under strong gravity field.

\section{REFERENCES}

1. K. Hatada, T. Kitayama, and O. Vogl, Ed., "Macromolecular Design of Polymeric Material", Marcel Dekker, Inc., New York, N. Y., 1997, pp 139-161.

2. H. Yuki, K. Hatada, Y. Kikuchi, and T. Nii-nomi, J. Polym. Sci., Part B, Polym, Lett., 6, 753 (1968).

3. M. Nishihara, T. Sagawa, H. Ihara, R. Nishimura, S. Matsuzaki, and T. Mashimo, J. Jpn. Soc. Powder Powder Metal., 47, 1201 (2000).

4. V. Briskman, K. Kostarev, V. Levtov, T. Lyubimova, A. Mashinsky, G. Nechitailo, and V. Romanov, Acta Astronautica, 39, 395 (1996).

5. T. Mashimo, Philos. Mag. A, 70, 739 (1994).

6. T. Mashimo, S. Okazaki, and S. Shibazaki, Rev. Sci. Instrum., 67, 3170 (1996).

7. T. Mashimo, S. Okazaki, and S. Tashiro, Jpn. J. Appl. Phys., 36, 498 (1997).

8. A. J. White and F. E. Filisco, J. Polym. Sci., Polym. Lett. Ed., 20, 525 (1982).

9. S. L. Regen, J. Shin, and K. Yamaguchi, J. Am. Chem. Soc., 106, 2446 (1984).

10. H. Asai and T. Imoto, Nippon Kagaku Kaishi, 84, 868 (1963). 